\title{
A COX-2 inhibitor enhances the antitumor effects of chemotherapy and radiotherapy for esophageal squamous cell carcinoma
}

\author{
GULBOSTAN YUSUP ${ }^{1}$, YASUNORI AKUTSU ${ }^{1}$, MURADIL MUTALLIP ${ }^{2}$, WEI QIN $^{1}$, XIN HU $^{1}$, \\ AKI KOMATSU-AKIMOTO ${ }^{1}$, ISAMU HOSHINO ${ }^{1}$, NAOYUKI HANARI ${ }^{1}$, MIKITO MORI ${ }^{1}$, \\ NAOKI AKANUMA ${ }^{1}$, YUKA ISOZAKI ${ }^{1}$ and HISAHIRO MATSUBARA ${ }^{1}$ \\ Departments of ${ }^{1}$ Frontier Surgery and ${ }^{2}$ Otorhinolaryngology, Graduate School of Medicine, \\ Chiba University, Chiba 260-8670, Japan
}

Received December 2, 2013; Accepted January 21, 2014

DOI: 10.3892/ijo.2014.2300

\begin{abstract}
Cyclooxygenase-2 (COX-2) is a key enzyme of prostaglandin $(\mathrm{PG})$ synthesis that has been demonstrated to be overexpressed in several types of cancers. The function of COX-2 in tumor progression has been recently elucidated. In tumors in which COX-2 is overexpressed, the antitumor effects are suppressed. We examined the effects of celecoxib, a COX-2 inhibitor, in enhancing the antitumor effects of chemotherapy and radiotherapy for esophageal squamous cell carcinoma (ESCC) by reducing the COX-2 activity. We used the human esophageal squamous cell lines TE2 and T.Tn treated with celecoxib and 5-FU/radiation, after which cell viability assays were performed. Changes in the expressions of dihydropyrimidine dehydrogenase (DPD), orotate phosphoribosyl transferase (OPRT) mRNA and PGE2 were also measured. In addition, apoptotic changes, and the invasion and migration activity in both the celecoxib and 5-FU treated cells were evaluated. The experiments showed that T.Tn and TE2 proliferation was strongly inhibited by the combination of 5-FU/radiation and the COX-2 inhibitor. Inhibiting the COX-2 activity induced a reduction in PGE2 levels in TE2/T.Tn cells. Following treatment with the COX-2 inhibitor and 5-FU, the OPRT expression was upregulated and the DPD expression was downregulated in the resistant cells. In addition, the combination treatment with the COX-2 inhibitor and 5-FU markedly inhibited both the cell invasion and migration activity. Therefore, COX-2 inhibitors can be useful enhancers of antitumor drugs and radiotherapy for ESCC.
\end{abstract}

Correspondence to: Dr Yasunori Akutsu, Department of Frontier Surgery, Graduate School of Medicine, Chiba University, 1-8-1, Inohana, Chuo-ku, Chiba 260-8670, Japan

E-mail: yakutsu@faculty.chiba-u.jp

Key words: cyclooxygenase-2, cyclooxygenase-2 inhibitor, celecoxib, squamous cell carcinoma, esophageal cancer

\section{Introduction}

Esophageal cancer is a highly aggressive neoplasm with a very poor prognosis. The primary treatments of esophageal cancer include surgery, chemotherapy and radiotherapy (1). In patients with locoregional esophageal cancer, surgical resection provides the best chance for a cure. However, in inoperable cases, chemoradiotherapy (CRT) is extremely important, although the 5 -year survival rate remains poor $(1,2)$. Therefore, the most important issue is how to improve the therapeutic effects of treatment.

Cyclooxygenase (COX), which consists of two isoforms, COX-1 and COX-2, is a key enzyme that catalyzes the transformation of arachidonic acid to prostaglandins (3). It is well known that COX-1 is expressed in many tissues and is responsible for various physiological functions $(3,4)$. On the other hand, recent studies have demonstrated that COX-2 is overexpressed in various malignancies, including pancreatic, gastric, prostate, lung, colon, breast, liver, brain and esophageal cancer (5-10). Recently, it has been reported that the overexpression of COX-2 induced tumor progression and promotes resistance to apoptosis activating various factors (11-13). We previously reported that the overexpression of COX-2 is closely correlated with resistance to chemoradiotherapy (CRT) for esophageal squamous cell carcinoma (ESCC) (14). Therefore, reducing the activity of COX-2 may enhance the antitumor effects of CRT for ESCC (14).

The non-steroidal anti-inflammatory drug (NSAID) celecoxib (a selective COX-2 inhibitor) belongs to the class of diaryl heterocycles and constitutes a potent and specific inhibitor of human COX-2 (15), which is responsible for resistance to apoptosis, tumor growth, increased angiogenesis, tumor invasion and metastasis (15-19).

We evaluated the usefulness of the COX-2 inhibitor celecoxib in combination with treatment including radiation and chemotherapy for ESCC.

\section{Materials and methods}

Cell culture and drugs. The esophageal squamous cell lines TE2 and T.Tn were plated in culture bottles and cultured 
in Dulbecco's modified Eagle's medium nutrient mixture (DMEM; Sigma, St. Louis, MO, USA) with $10 \%$ fetal bovine serum (FBS) and $5 \mathrm{mmol} / \mathrm{l}$ of L-glutamine, and $100 \mathrm{U} / \mathrm{ml}$ of penicillin at $37^{\circ} \mathrm{C}$ in a $5 \% \mathrm{CO}_{2}$ atmosphere.

Celecoxib (a COX-2 inhibitor) kindly provided by Compound Transfer, Research and Development Operations, Pfizer Inc., New York, NY, USA, was dissolved in dimethyl sulfoxide (DMSO). 5-Fluorouracil (5-FU) was purchased from Sigma and dissolved in DMEM (5\% P/S, 10\% FBS).

Viability of cells treated with celecoxib and/or 5-FU. First, the TE2 and T.Tn cell lines were plated in 96-well plates at a density of 3,000 cell/well for $24 \mathrm{~h}$ after seeding. Then, the cell lines were cultured with varying concentrations of celecoxib and/or 5-FU for $72 \mathrm{~h}$. Following these treatments, $10 \mu \mathrm{l} /$ well of the Cell Counting Kit- 8 was added, and the cells were incubated for $2 \mathrm{~h}$. Finally, the optical density at $450 \mathrm{~nm}$ in the multi-mode micro-plate reader was measured in triplicate. The cell viability was calculated using the following equation: cell viability $(\%)=($ A experimental group $-\mathrm{A}$ control group)/A control group x $100 \%$.

Drug treatment and irradiation. First, the cells were plated in 96-well plates and treated with varying concentrations of celecoxib for $72 \mathrm{~h}$. The cells were cultured after irradiation, combined with celecoxib treatment for five days. After these treatments, $10 \mu \mathrm{l} /$ well of the Cell Counting Kit- 8 was added, and the cells were incubated for $2 \mathrm{~h}$. Finally, the optical density at $450 \mathrm{~nm}$ in the multi-mode micro-plate reader was measured in triplicate.

Observation of apoptosis using flow cytometry. A total of four groups, including the control and experimental groups, were evaluated for apoptosis. When the cells grew to the logarithmic phase, they were treated with $50 \mu \mathrm{mol} / 1$ of $5-\mathrm{FU}$, or $10 \mu \mathrm{mol} / \mathrm{l}$ of celecoxib, or both for $48 \mathrm{~h}$. After this treatment, the cells were digested with $0.25 \%$ trypsin to create single cell suspensions. After the cell density was adjusted to $5 \times 10^{5} / 100 \mu \mathrm{l}$ of binding buffer, $5 \mu \mathrm{l}$ of Annexin V-FITC and $5 \mu \mathrm{l}$ of propidium iodide were added and the mixture was gently vortexed followed by incubation for another $15 \mathrm{~min}$ at room temperature in the dark. After this procedure, a volume of $400 \mu \mathrm{l}$ of binding buffer was added to each tube and prepared for an analysis of apoptosis using flow cytometry within $1 \mathrm{~h}$.

Measurement of the $m R N A$ levels using real-time reverse transcription polymerase chain reaction ( $R T-P C R)$ for dihydropyrimidine dehydrogenase (DPD) and orotate phosphoribosyl transferase (OPRT). The cells were incubated for $48 \mathrm{~h}$ with either celecoxib or 5-FU and/or both. The RNA was extracted using TRIzol ${ }^{\circledR}$ Reagent (Invitrogen, Carlsbad, CA, USA), and $1 \mu \mathrm{g}$ of RNA was transcribed to cDNA using a High-Capacity RNA-to-cDNA kit (Applied Biosystems, Foster City, CA, USA). The resulting $1 \mu \mathrm{l}$ of cDNA was amplified via PCR. The sequence and size of the expected PCR products were as follows: DPD (sense, 5'-AGGACGCAAGGAGG GTTTG-3'; antisense, 5'-GTCCGCCGAGTCCTTACTGA-3'; 118 bp), OPRT (sense, 5'-TAGTGTTTTGGAAACTGTTG AGGTT-3'; antisense, 5'-CTTGCCTCCCTGCTCTCTGT-3'; $91 \mathrm{bp}$ ) and $\beta$-actin (sense, 5'-TCATGAAGATCCTCAC

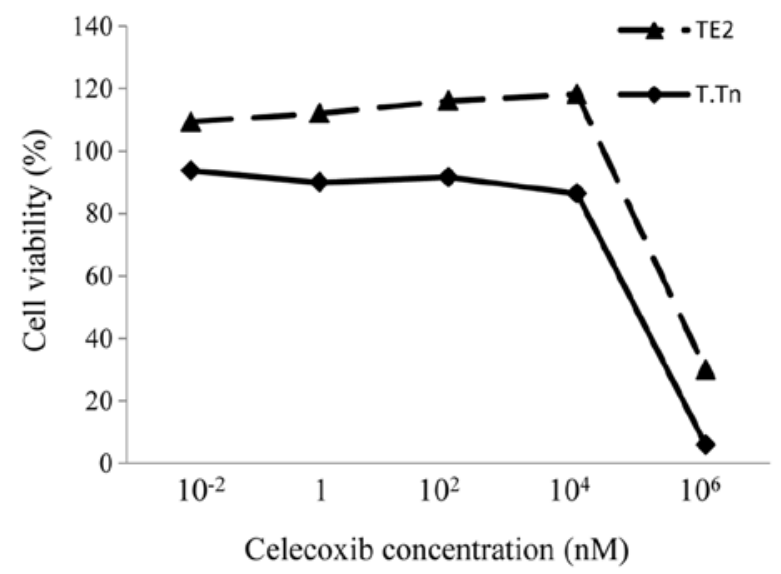

Figure 1. Viability of the cells treated with celecoxib alone. The cells were treated with varying concentrations of celecoxib, and the cell viability was evaluated. Celecoxib alone did not exhibit any antitumor effects under the normal range of concentrations.

CGAG-3'; antisense, 5'-TTGCCAATGGTGATGACCTG-3'; $190 \mathrm{bp})$. The PCR conditions consisted of 40 cycles of $95^{\circ} \mathrm{C}$ for $30 \mathrm{sec}, 95^{\circ} \mathrm{C}$ for $5 \mathrm{sec}, 60^{\circ} \mathrm{C}$ for $10 \mathrm{sec}$. This assay was performed in triplicate.

Cell migration and invasion assay. A membrane invasion culture system (BD BioCoat ${ }^{\mathrm{TM}}$ Matrigel $^{\mathrm{TM}}$ Invasion Chamber, Tokyo, Japan) was used to quantify the degree of cell invasion and migration. The cells were incubated for $72 \mathrm{~h}$ with either celecoxib or 5 -FU or both. A total of $4 \times 10^{4}$ cells in $500 \mu 1$ of serum-free medium were added to the upper chamber of the Transwell-precoated Matrigel membrane filter inserts with $8-\mu \mathrm{m}$ pores in 24-well tissue culture plates. A total of $750 \mu \mathrm{l}$ of $10 \%$ FBS medium was added to the lower chamber. Thereafter the cells were incubated for $22 \mathrm{~h}$ at $37^{\circ} \mathrm{C}$. Following incubation, the non-invading cells were mechanically removed from the upper surface of the membrane. Subsequently, the cells were fixed and stained with $100 \%$ methanol and $1 \%$ Toluidine, blue or $0.25 \%$ crystal violet. Next, the membrane was washed with distilled water to remove excess staining and dried. The cells on the lower surface were counted manually under a microscope. This assay was performed in triplicate.

ELISA for prostaglandin E2. The cells were incubated for 24, 48 and $72 \mathrm{~h}$ with celecoxib $(0,10,20,30 \mu \mathrm{M})$. The PGE2 levels were measured using an enzyme-linked immunosorbent assay (ELISA) as described by PGE2 Prostaglandin E2, EIA Kit - Monoclonal (Cayman Chemical Company, Ann Arbor, MI, USA) according to the manual. The concentrations were determined following absorbance measurement with a micro-plate reader (micro-plate manager version 6.0, Bio-Rad, Tokyo, Japan). This assay was performed in triplicate.

\section{Results}

Cytotoxicity of celecoxib in the TE2 and T.Tn cells. The TE2 and T.Tn cells were treated with different concentrations of celecoxib for $72 \mathrm{~h}$, and the cell viability was evaluated. There was no toxicity in the cells treated with concentrations $10^{-2}$ and 
A

TE2

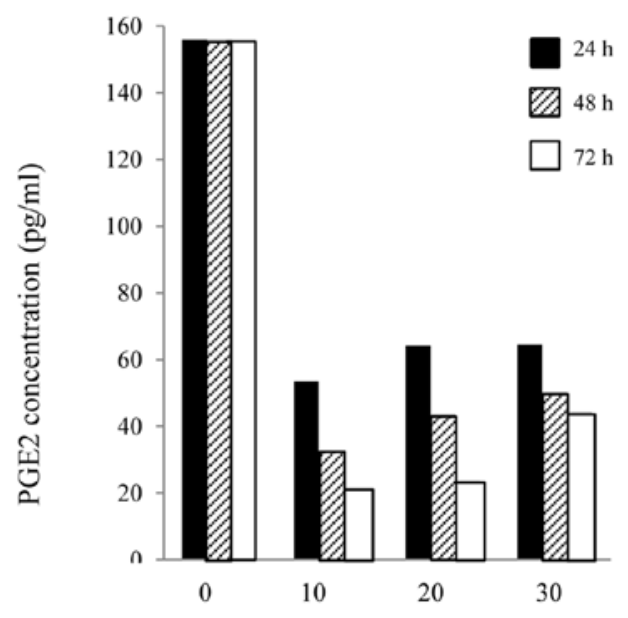

Celecoxib concentration $(\mu \mathrm{M})$
B

T.Tn

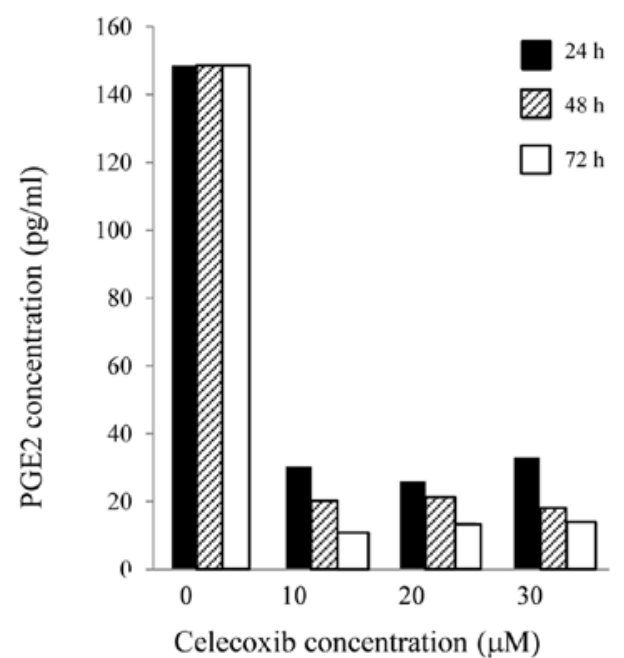

Figure 2. Serum levels of PGE2 in the TE2 (A) and T.Tn (B) cells after treatment with celecoxib. Celecoxib treatment in the TE2 and T.Tn cells during the growth process exhibited obvious inhibitory effects on the PGE2 levels.

A

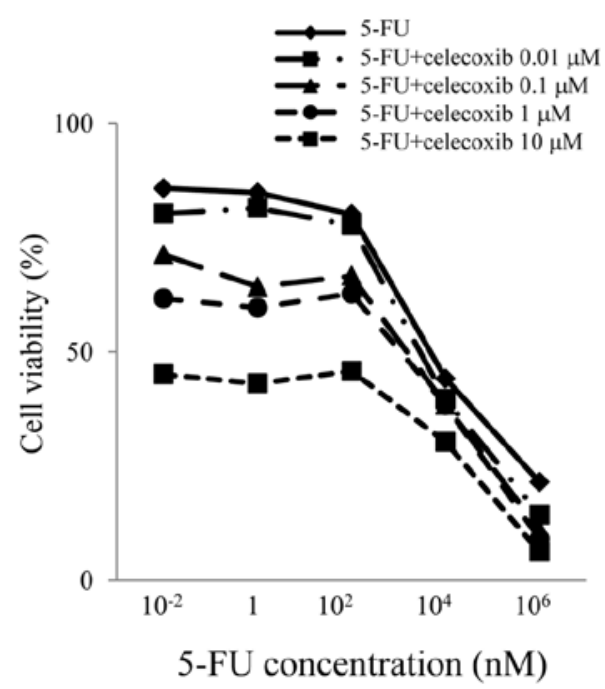

B T.Tn

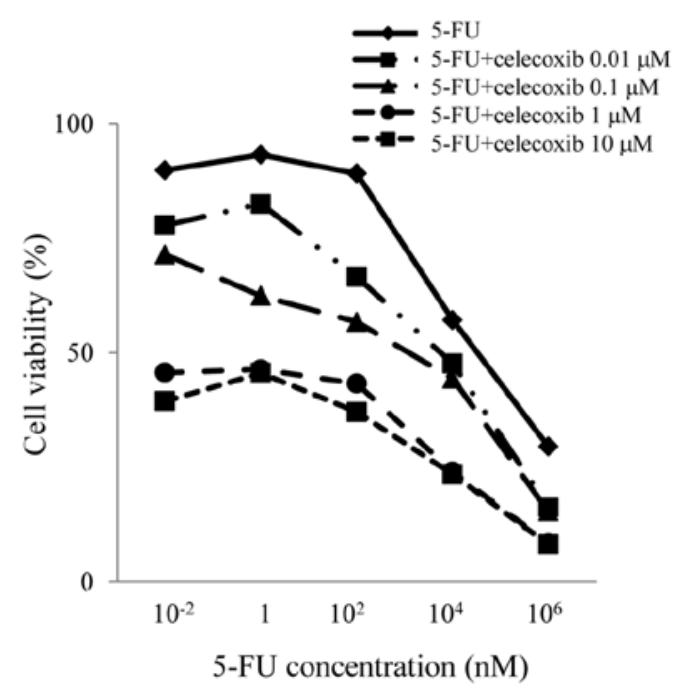

Figure 3. Viability of the TE2 (A) and T.Tn (B) cells treated with 5-FU and celecoxib. The proliferation of the T.Tn and TE2 cancer cells was inhibited more strongly by the combination of 5-FU and celecoxib.

$10^{4} \mathrm{nM}$ (Fig. 1). However, when the concentration increased to $10^{6} \mathrm{nM}$, the cell viability was strongly reduced. This finding shows that celecoxib itself does not exhibit any antitumor effects under the normal range of concentrations.

Serum levels of PGE2 in the TE2/T.Tn cells following treatment with celecoxib. In this study, the PGE2 levels in the TE2 and T.Tn cells were determined using ELISA. As shown in Fig. 2, celecoxib exhibited obvious inhibitory effects on PGE2 in the TE2 and T.Tn cells during the growth process, especially as the drug exposure time was extended, compared with the normal growth of cancer cells. The production of PGE2 was also significantly reduced.
Cytotoxicity of TE2 and T.Tn to 5-FU and celecoxib. To investigate whether celecoxib can potentiate the cytotoxic effects of 5-FU in the two cell lines, cytotoxic assays were conducted. As shown in Fig. 3, in the TE2 cell line, no antitumor effects were observed between 0 and $100 \mathrm{nM}$ of 5-FU treatment alone. However, when adding celecoxib, the antitumor effects were enhanced in a celecoxib concentrationdependent manner. This indicated that celecoxib enhances the antitumor effects of 5-FU even when the concentration of 5-FU is low.

Viability of TE2/T.Tn cells treated with radiation and celecoxib. The TE2 and T.Tn cells were cultured with celecoxib in addi- 
A

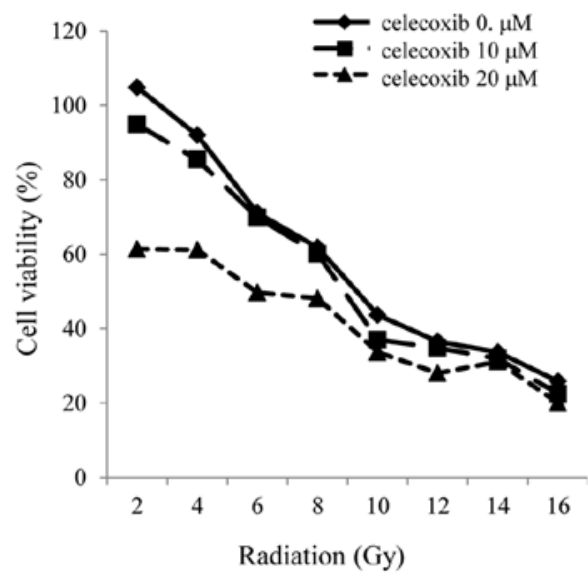

B T.Tn

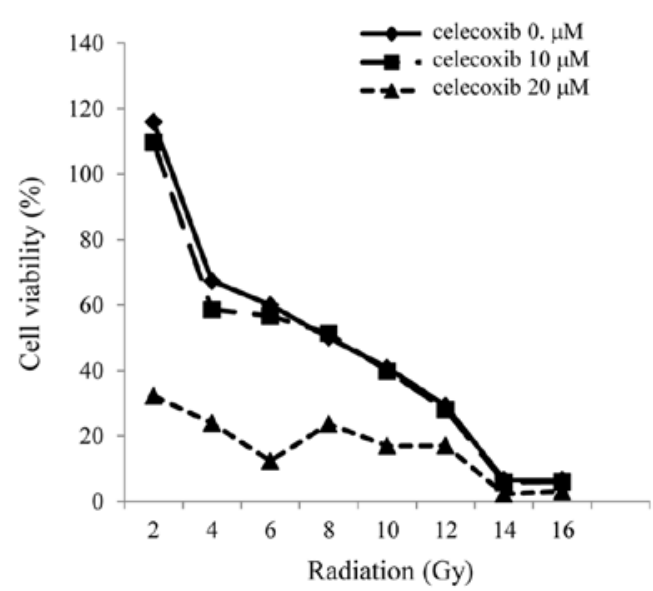

Figure 4. Viability of the TE2 (A) and T.Tn (B) cells treated with radiation and celecoxib. Increased radiation sensitivity was observed following the introduction of celecoxib.

A

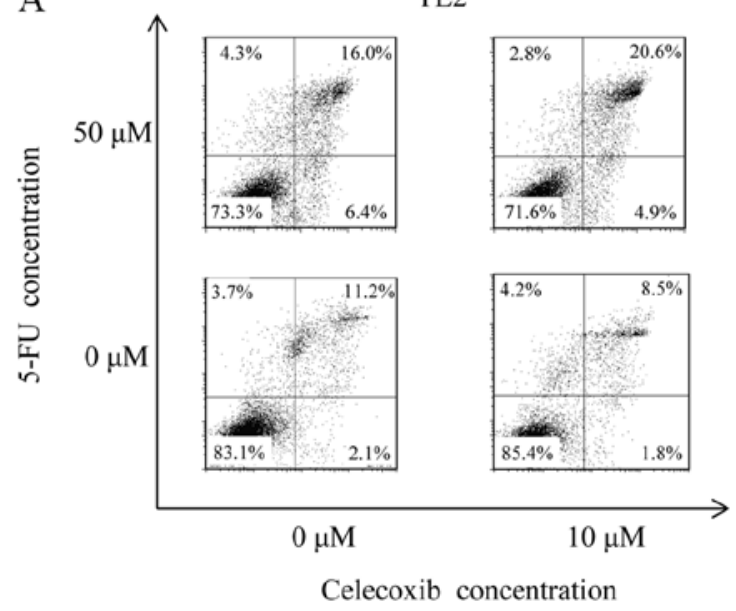

B

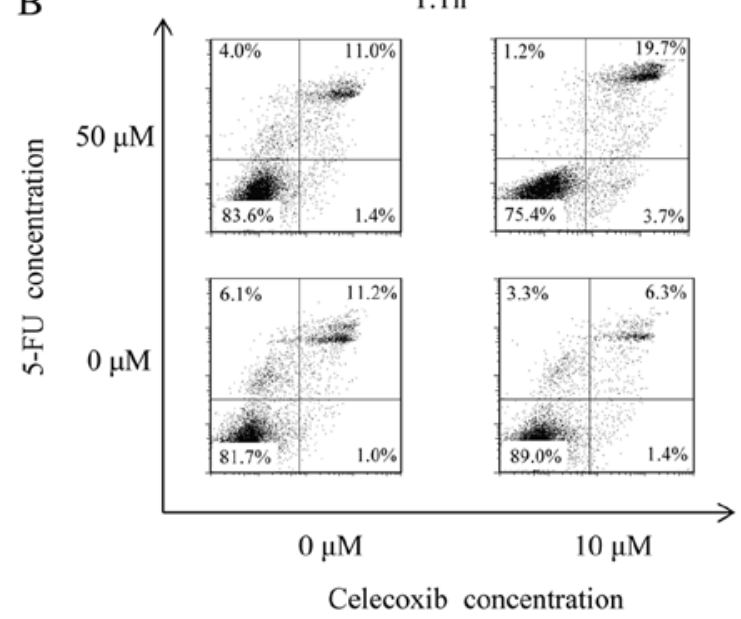

Figure 5. Apoptosis following treatment with 5-FU and celecoxib. A significant increment in the population of apoptotic cells was observed when the cells were cultured with both celecoxib and 5-FU. Better results were obtained than that observed in the celecoxib alone and control groups.

tion to receiving irradiation, after which the cell viability was evaluated. There was enhancement of the antitumor effects in the TE2 cells cultured with the COX-2 inhibitor at $20 \mu \mathrm{M}$ compared to that observed in the cells exposed to radiation alone. The discrepancy in cell viability between the radiation alone group and the radiation plus celecoxib group increased in the range of lower doses of radiation, especially after the radiation. The same result was found in the T.Tn cells, at an even higher level than that observed in the TE2 cells (Fig. 4).

Apoptosis induced by celecoxib and 5-FU. The Annexin V FITC/PI double-labeling method was performed to detect apoptotic cells. As shown in Fig. 5, the flow cytometry analysis demonstrated no differences in the Annexin V+PI+ cell population between the TE2 cells cultured with celecoxib alone $(10 \mu \mathrm{M})(8.54 \%)$ and the control group (11.2\%). On the other hand, a significant increment in the population of apoptotic cells was observed when the cells were cultured with both celecoxib and 5-FU (20.6\%). The same result was found in the T.Tn cells at an even higher level than that observed in the TE2 cells.

Expressions of OPRT and DPD following treatment with celecoxib. 5-FU was metabolized to the nucleotide level, and DPD and OPRT are important metabolic enzymes for 5-FU. As shown in Fig. 6, the expression of DPD, a degenerative enzyme for 5-FU, was lower (70\%) in the TE2 and T.Tn cells than in the control group when treated with combination of celecoxib and 5-FU. With regard to the OPRT expression, an approximately 2.5 -fold increase was observed in the TE2 cells and an approximately 5 -fold increase was observed in the T.Tn cells. Based on these data, celecoxib reduces the degeneration of 5-FU and increases the metabolism of 5-FU with stronger antitumor effects by modifying 5-FU-related enzymes, accordingly. This mechanism can be used to explain the effects of celecoxib in enhancing the antitumor effects of 5-FU. 
DPD

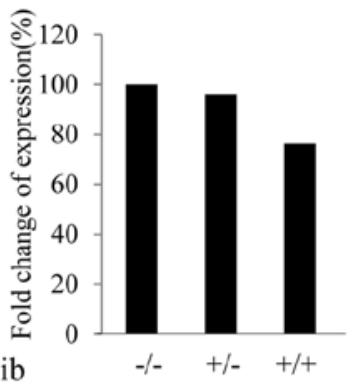

5-FU $(10 \mu \mathrm{M}) /$ Celecoxib

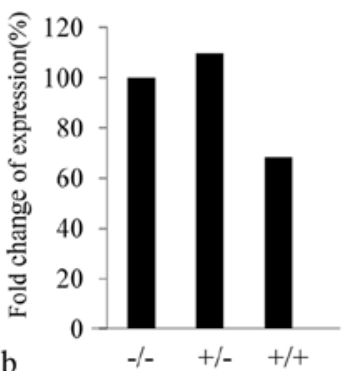

TS
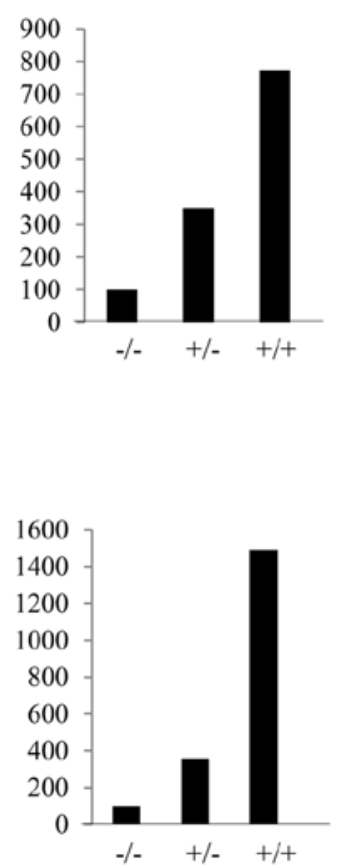

OPRT
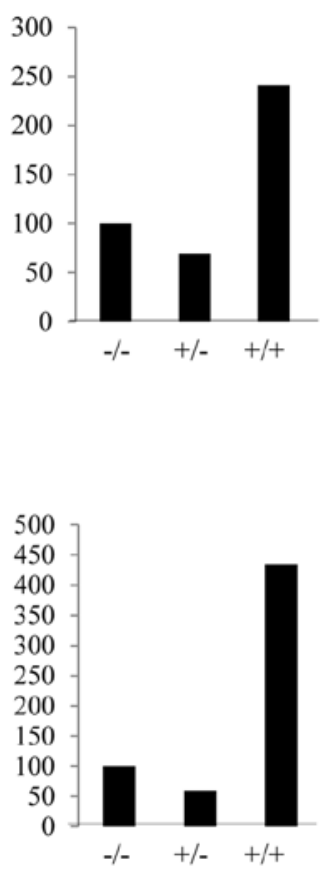

Figure 6. Expressions of DPD and OPRT in the TE2/T.Tn cells. Celecoxib up-regulated the OPRT expressions and down-regulated the DPD expression. This mechanism can be used to explain the effects of celecoxib in enhancing the antitumor effects of 5-FU.

A

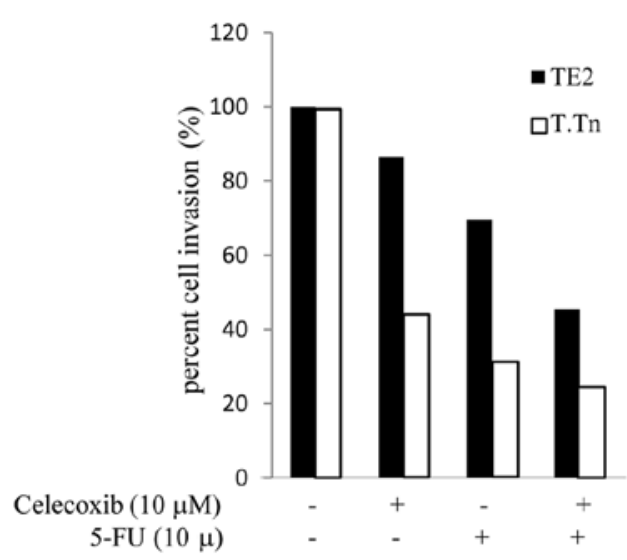

B

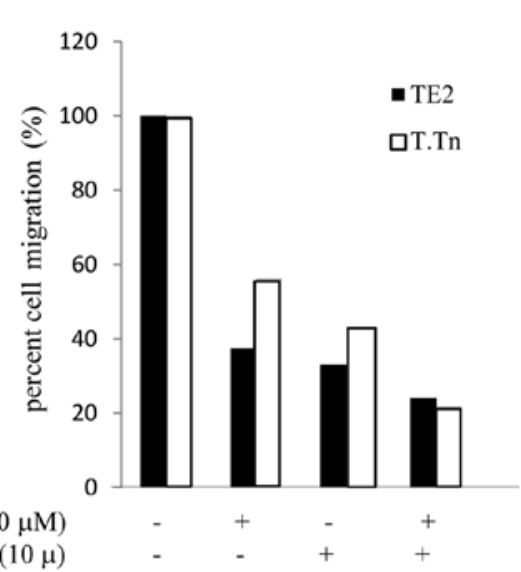

Figure 7. Cell migration and invasion in the TE2 and T.Tn cells following treatment with 5-FU and celecoxibin. Combination treatment with celecoxib and 5-FU inhibited both the cell invasion (A) and migration (B) activity.

Effects of celecoxib on the cell invasion and migration potential. The cell migration and invasion activity in the TE2 and T.Tn cells following treatment with 5-FU and celecoxib is shown in Fig. 7. In the TE2 cells, treated with celecoxib alone, the cell invasion activity was $86.5 \%$ compared to that observed in the control cells. When cultured with 5-FU alone, the cell invasion activity was reduced to $69.5 \%$ compared to that observed in the controls. However, when cultured with both celecoxib and 5-FU, the inhibition rate was markedly reduced to $45.4 \%$ (Fig. 7A). This trend was also observed in the T.Tn cells (celecoxib alone, 44.2\%; 5-FU alone, 31.3\%; combination group, 25.1\%). Next, in order to quantify the cell migration levels, the cells were treated with either 5-FU or celecoxib, or both (Fig. 7B). In the T.Tn cells, when treated with celecoxib alone, the migration activity was reduced to $56.3 \%$. When treated with 5-FU alone, the invasion rate was $43.1 \%$. However, when cultured with both celecoxib and 5-FU, the migration activity was markedly reduced to $21.8 \%$ compared to that observed in the control group. This trend was also observed in the TE2 cells (celecoxib alone, 37.5\%; 5-FU alone, $33.1 \%$; combination group, 24\%). These results indicated that celecoxib enhances the inhibition of both the invasion and migration activity induced 5-FU. 


\section{Discussion}

The long-term use of non-steroidal anti-inflammatory drugs (NSAIDs) can reduce the risk of cancer and inhibit the growth of various cancers, including squamous cell carcinoma (7). The primary target of NSAIDs is COX-2, which is responsible for resistance to apoptosis, tumor growth, increased angiogenesis, tumor invasion and metastasis $(16,17)$. Elevated levels of the COX-2 expression have been found in human cancers (5-10), and appear to be involved in the development of cancer via PGE2 production (7,20-23). In addition, COX-2 overexpression is often associated with a shorter time to progression and/or overall survival (24). The function of COX-2 in tumor progression has been recently elucidated. To date, at least five mechanisms by which COX-2 contributes to tumorigenesis and the malignant phenotype of tumor cells have been identified, including inhibition of apoptosis, increased invasiveness, increased angiogenesis, modulation of inflammation/immunesuppression and conversion of procarcinogens to carcinogens (5). Research regarding the role of COX-2 in cancer prevention and tumor progression inhibition is ongoing. With respect to treatment effects, the overexpression of COX-2 leads to tolerance of treatments such as chemotherapy and chemoradiotherapy, as we previously reported (14).

5-Fluorouracil (5-FU) is one of the most common and effective clinical chemotherapy medications for the treatment of digestive tract tumors, with a specific set of effects. The primary mechanism of action consists of interfering with DNA synthesis and mRNA translation (25). 5-FU metabolism is primarily regulated by enzymes, such as DPD and OPRT (25-27). The rate-limiting enzyme of 5-FU catabolism is DPD, as more than $80 \%$ of administered 5-FU is catabolized by DPD (26). Measuring the level of DPD activity can be used as a screening procedure to identify patients with DPD deficiency, before the start of treatment with 5-FU (27). The metabolized form of 5-FU is directly converted by OPRT, and further dephosphorylated to generate the active metabolite fluorodeoxyuridine monophosphate (FdUMP) which binds to the nucleotide-binding site of TS and forms a stable ternary complex with TS and 5,10-methylenetetrahydrofolate (5,10$\mathrm{CH} 2-\mathrm{THF}$ ), leading to DNA damage (25).

The present study demonstrated that COX-2, was upregulated in the 5-FU resistant esophageal cancer cell lines. Although celecoxib, a COX-2 inhibitor, exhibited very slight anticancer effects in the TE2/T.Tn cells, stronger anticancer effect was observed following changes in the DPD and OPRT levels in the 5-FU resistant esophageal cancer cell lines.

In this study, celecoxib inhibited the COX-2 activity, leading to a reduction in the PGE2 levels in the cancer cells. This indicates that B-cell lymphoma-2 (BCL-2), matrix metalloproteinase-2 (MMP-2), epidermal growth factor receptor (EGFR), endothelial growth factor (VEGF) and other factors are restrained by COX-2-PGE2-dependent mechanisms (28-31). However, Elder et al reported no correlations between the sensitivity of colon cancer cell lines to NS-398 and the COX-2 expression or between the addition of PGE2 and the induction of apoptosis (32). This discrepancy may represent differences between the cells analyzed by different investigators and the types of NSAIDs used. On the other hand, celecoxib upregulates the OPRT expression and downregulates the DPD expression, which may increase the antitumor effects of 5-FU and can inhibit the growth of tumor cells or increase the apoptosis of cancer cells and inhibit cancer cell migration and invasion. Consequently, the changes in the reduction of the enzyme activity observed in experimental systems exhibit good relationships with the enhancement of the antiproliferative potency of 5-FU. However, thus far, it is unclear through which factors and pathways COX-2 inhibitors can change the expressions of DPD and OPRT mRNA. In their in vivo research, Irie et al reported that celecoxib (a selective COX-2 inhibitor) synergistically potentiates the antitumor effects of 5-FU in colon cancer cells in an IFN- $\gamma$-dependent manner (33).

In addition, we tested the effects of combination therapy with celecoxib and radiation in TE2 and T.Tn cells. The results showed that the effects of combination therapy are stronger than those of radiotherapy alone. Our experimental results are supported by those of Kuipers et al (34). Previous studies have revealed that these effects are due to cell cycle arrest. Radiosensitivity enhancement using a COX-2 inhibitor is achieved through COX-2-dependent cell cycle regulation (35) and primarily results from the inhibition of ionizing radiation-induced $\mathrm{G} 2$ arrest (36). It has also been suggested that these effects are likely due to the inhibition of the radioprotective effects of prostaglandins (37). Other mechanisms have also been elucidated. COX-2 inhibitors contribute to the enhancing antitumor effects via the activation of caspase- 3 and caspase- 8 or the inhibition of DNA repair processes $(38,39)$.

In conclusion, resistance to cancer treatment can be decreased by COX-2 inhibitors. COX-2 inhibitors are useful enhancers of antitumor drugs and act as radiosensitizers for radiotherapy for ESCC. Therefore, these drugs may be useful as a component of combination treatment for cancer.

\section{References}

1. Pennathur A, Gibson MK, Jobe BA and Luketich JD: Oesophageal carcinoma. Lancet 381: 400-412, 2013.

2. Siersema PD: Esophageal cancer. Gastroenterol Clin North Am 37: 943-964, 2008.

3. Rizzo MT: Cyclooxygenase-2 in oncogenesis. Clin Chim Acta 412: 671-687, 2011.

4. Smith WL, DeWitt DL and Garavito RM: Cyclooxygenases: structural, cellular, and molecular biology. Annu Rev Biochem 69: 145-182, 2000.

5. Dempke W, Rie C, Grothey A and Schmoll HJ: Cyclooxygenase-2: a novel target for cancer chemotherapy? J Cancer Res Clin Oncol 127: 411-417, 2001.

6. Shamma A, Yamamoto H, Doki Y, et al: Up-regulation of cyclooxygenase-2 in squamous carcinogenesis of the esophagus. Clin Cancer Res 6: 1229-1238, 2000.

7. Hida T, Yatabe Y, Achiwa H, et al: Increased expression of cyclooxygenase 2 occurs frequently in human lung cancers, specifically in adenocarcinomas. Cancer Res 58: 3761-3764, 1998.

8. Dannenberg AJ and Subbaramaiah K: Targeting cyclooxygenase-2 in human neoplasia: rationale and promise. Cancer Cell 4: 431-436, 2003.

9. Okamura H, Fujiwara H, Umehara S, et al: COX-2 overexpression Induced by gene transfer reduces sensitivity of TE13 esophageal carcinoma cells to 5-fluorouracil and cisplatin. Anticancer Res 33: 537-542, 2013.

10. Higashi Y, Kanekura T and Kanzaki T: Enhanced expression of cyclooxygenase (COX)-2 in human skin epidermal cancer cells: evidence for growth suppression by inhibiting COX-2 expression. Int J Cancer 86: 667-671, 2000.

11. Lucci A, Krishnamurthy S, Singh B, et al: Cyclooxygenase-2 expression in primary breast cancers predicts dissemination of cancer cells to the bone marrow. Breast Cancer Res Treat 117: 61-68, 2009. 
12. Van Nes JG, de Kruijf EM, Faratian D, et al: COX2 expression in prognosis and in prediction to endocrine therapy in early breast cancer patients. Breast Cancer Res Treat 125: 671-685, 2011.

13. Hashimoto N, Inayama M, Fujishima $M$ and Shiozaki $H$ : Clinicopathologic significance of expression of cyclooxygenase-2 in human esophageal squamous cell carcinoma. Hepatogastroenterology 54: 758-760, 2007.

14. Akutsu Y, Hanari N, Yusup G, et al: COX2 expression predicts resistance to chemoradiotherapy in esophageal squamous cell carcinoma. Ann Surg Oncol 18: 2946-2951, 2011.

15. Jendrossek V: Targeting apoptosis pathways by Celecoxib in cancer. Cancer Lett 332: 313-324, 2013.

16. Boolbol SK, Dannenberg AJ, Chadburn A, et al: Cyclooxygenase-2 overexpression and tumor formation are blocked by sulindac in a murine model of familial adenomatous polyposis. Cancer Res 56: 2556-2560, 1996.

17. Tsujii M, Kawano S and DuBois RN: Cyclooxygenase-2 expression in human colon cancer cells increases metastatic potential. Proc Natl Acad Sci USA 94: 3336-3340, 1997.

18. Kwak YE, Jeon NK, Kim J and Lee EJ: The cyclooxygenase-2 selective inhibitor celecoxib suppresses proliferation and invasiveness in the human oral squamous carcinoma. Ann NY Acad Sci 1095: 99-112, 2007.

19. Dai ZJ, Ma XB, Kang HF, et al: Antitumor activity of the selective cyclooxygenase-2 inhibitor, celecoxib, on breast cancer in vitro and in vivo. Cancer Cell Int 12: 53, 2012.

20. Soslow RA, Dannenberg AJ, Rush D, et al: COX-2 is expressed in human pulmonary, colonic, and mammary tumors. Cancer 89: 2637-2645, 2000

21. Gupta S, Srivastava M, Ahmad N, Bostwick DG and Mukhtar H: Over-expression of cyclooxygenase-2 in human prostate adenocarcinoma. Prostate 42: 73-78, 2000

22. Sano H, Kawahito Y, Wilder RL, et al: Expression of cyclooxygenase-1 and -2 in human colorectal cancer. Cancer Res 55: $3785-3789,1995$

23. Hwang D, Scollard D, Byrne J and Levine E: Expression of cyclooxygenase-1 and cyclooxygenase- 2 in human breast cancer. J Natl Cancer Inst 90: 455-460, 1998.

24. De Groot DJ, de Vries EG, Groen HJ and de Jong S: Non-steroidal anti-inflammatory drugs to potentiate chemotherapy effects: from lab to clinic. Crit Rev Oncol Hematol 61: 52-69, 2007.

25. Takemura M, Morimura K, Yoshida K and Fujiwara Y: Four resected cases with basaloid carcinoma of esophagus - comparison of 5-FU-related enzymes (thymidylate synthase (TS), dihydropyrimidine dehydrogenase (DPD), orotate phosphoribosyl transferase (OPRT)) between basaloid carcinoma and squamous cell carcinoma. Gan To Kagaku Ryoho 37: 2143-2146, 2010 (In Japanese).

26. Ofverholm A, Arkblad E, Skrtic S, Albertsson P, Shubbar E and Enerback C: Two cases of 5-fluorouracil toxicity linked with gene variants in the DPYD gene. Clin Biochem 43: 331-334, 2010.

27. Ostapowicz A and Dolegowska B: Review of methods for determination of dihydropyrimidine dehydrogenase and possible application in screening previous chemotheraphy with 5-fluorouracil. Przegl Lek 69: 694-697, 2012 (In Polish).
28. Li WZ, Huo QJ, Wang XY and Xu F: Inhibitive effect of celecoxib on the adhesion and invasion of human tongue squamous carcinoma cells to extracellular matrix via down regulation of MMP-2 expression. Prostaglandins Other Lipid Mediat 93: 113-119, 2010.

29. Sheng H, Shao J, Morrow JD, Beauchamp RD and DuBois RN: Modulation of apoptosis and $\mathrm{Bcl}-2$ expression by prostaglandin E2 in human colon cancer cells. Cancer Res 58: $362-366,1998$

30. Oshima $\mathrm{H}$ and Oshima M: The role of PGE2-associated inflammatory responses in gastric cancer development. Semin Immunopathol 35: 139-150, 2013.

31. Cianchi F, Cortesini C, Bechi P, et al: Up-regulation of cyclooxygenase 2 gene expression correlates with tumor angiogenesis in human colorectal cancer. Gastroenterology 121: 1339-1347, 2001.

32. Elder DJ, Halton DE, Crew TE and Paraskeva C: Apoptosis induction and cyclooxygenase-2 regulation in human colorectal adenoma and carcinoma cell lines by the cyclooxygenase2 -selective non-steroidal anti-inflammatory drug NS-398. Int J Cancer 86: 553-560, 2000.

33. Irie T, Tsujii M, Tsuji S, et al: Synergistic antitumor effects of celecoxib with 5-fluorouracil depend on IFN-gamma. Int J Cancer 121: 878-883, 2007.

34. Kuipers GK, Slotman BJ, Wedekind LE, et al: Radiosensitization of human glioma cells by cyclooxygenase-2 (COX-2) inhibition: independent on COX-2 expression and dependent on the COX-2 inhibitor and sequence of administration. Int J Radiat Biol 83: 677-685, 2007.

35. Shin YK, Park JS, Kim HS, et al: Radiosensitivity enhancement by celecoxib, a cyclooxygenase (COX)-2 selective inhibitor, via COX-2-dependent cell cycle regulation on human cancer cells expressing differential COX-2 levels. Cancer Res 65: 9501-9509, 2005.

36. Jun HJ, Kim YM, Park SY, et al: Modulation of ionizing radiation-induced G2 arrest by cyclooxygenase-2 and its inhibitor celecoxib. Int J Radiat Oncol Biol Phys 75: 225-234, 2009.

37. Davis TW, O'Neal JM, Pagel MD, et al: Synergy between celecoxib and radiotherapy results from inhibition of cyclooxygenase-2-derived prostaglandin E2, a survival factor for tumor and associated vasculature. Cancer Res 64: 279-285, 2004.

38. Kim BM, Won J, Maeng KA, Han YS, Yun YS and Hong SH: Nimesulide, a selective COX-2 inhibitor, acts synergistically with ionizing radiation against A549 human lung cancer cells through the activation of caspase- 8 and caspase-3. Int J Oncol 34: 1467-1473, 2009

39. Raju U, Ariga H, Dittmann K, Nakata E, Ang KK and Milas L: Inhibition of DNA repair as a mechanism of enhanced radioresponse of head and neck carcinoma cells by a selective cyclooxygenase-2 inhibitor, celecoxib. Int J Radiat Oncol Biol Phys 63: 520-528, 2005. 